\title{
A phase lb study to assess the efficacy and safety of vismodegib in combination with ruxolitinib in patients with intermediate- or high-risk myelofibrosis
}

Stephen Couban ${ }^{1,11^{*}}$, Giulia Benevolo², William Donnellan ${ }^{3}$, Jennifer Cultrera ${ }^{4}$, Steffen Koschmieder ${ }^{5}$, Srdan Verstovsek ${ }^{6}$, Gregory Hooper ${ }^{7}$, Christian Hertig ${ }^{8}$, Maneesh Tandon ${ }^{7}$, Natalie Dimier ${ }^{7}$, Vikram Malhi $^{9}$ and Francesco Passamonti ${ }^{10}$

\begin{abstract}
Background: The JAK inhibitor (JAKi) ruxolitinib is standard treatment for myelofibrosis (MF), but some patients are unresponsive. Pre-clinical and clinical data suggest that addition of a Hedgehog pathway inhibitor (HPI) to ruxolitinib might improve response. Vismodegib is an HPI approved for treatment of locally advanced and metastatic basal cell carcinoma. The MYLIE study assessed the safety and efficacy of combining ruxolitinib with vismodegib in ruxolitinib-naive patients with MF and characterized the pharmacokinetics (PK) of vismodegib in this setting.

Methods: In this phase Ib study, ten patients with intermediate- or high-risk primary or secondary MF received open-label vismodegib (150 mg/day orally) and ruxolitinib (15 or 20 mg orally twice daily, depending on baseline platelet count) for up to 48 weeks, or until withdrawal or discontinuation. PK samples were collected throughout the study for comparison with other patient populations. Efficacy outcomes at week 24 included spleen response ( $\geq 35 \%$ reduction in volume by imaging) and improvement in bone marrow fibrosis by central and investigator assessment, symptom response ( $\geq 50 \%$ reduction in Myeloproliferative Neoplasm Symptom Assessment Form Total Symptom score), and anemia response (per International Working Group for Myeloproliferative Neoplasms Research and Treatment revised response criteria).

Results: As of November 17, 2017, eight patients had completed 48 weeks of treatment with vismodegib and ruxolitinib; two discontinued treatment early. At week 24 ( \pm 1 week), three patients experienced a spleen response by central review and no patients showed a 1-grade improvement in bone marrow fibrosis by central review. Five patients experienced symptom response at week 24, and no patients experienced an anemia response. The most common adverse events were muscle spasm (100\% of patients), alopecia (70\%), dysgeusia (50\%), thrombocytopenia (50\%), and nausea (40\%); these events were predominantly grade 1/2. Three patients experienced a total of six serious adverse events.
\end{abstract}

Conclusions: The combination of vismodegib and ruxolitinib was tolerable and no new safety signals were seen, but there was no evidence that the addition of vismodegib to ruxolitinib improved any of the efficacy outcome measures assessed. Further evaluation of this combination will not be pursued.

Trial registration: ClinicalTrials.gov, NCT02593760. Registered November 2, 2015.

Keywords: Vismodegib, Ruxolitinib, Myelofibrosis, Hedgehog pathway inhibitor, Hematopoiesis, Hematologic malignances

\footnotetext{
* Correspondence: stephen.couban@nshealth.ca

'Queen Elizabeth II Health Sciences Centre, 1278 Tower Road, Room 420,

Halifax, Nova Scotia B3H 2V7, Canada

${ }^{11}$ Queen Elizabeth II Health Sciences Centre, Room 430, Bethune Building, VG

Site, 126 South Park Street, Halifax, Nova Scotia B3H 2V9, Canada

Full list of author information is available at the end of the article
}

(c) The Author(s). 2018 Open Access This article is distributed under the terms of the Creative Commons Attribution 4.0 International License (http://creativecommons.org/licenses/by/4.0/), which permits unrestricted use, distribution, and reproduction in any medium, provided you give appropriate credit to the original author(s) and the source, provide a link to the Creative Commons license, and indicate if changes were made. The Creative Commons Public Domain Dedication waiver (http://creativecommons.org/publicdomain/zero/1.0/) applies to the data made available in this article, unless otherwise stated. 
Table 1 Baseline characteristics

\begin{tabular}{ll}
\hline & $N=10$ \\
\hline Age, median (range), years & 67.5 (46-82) \\
Sex, $n$ & 7 \\
Male & 3 \\
Female & \\
ECOG performance status, $n$ & 4 \\
0 & 6 \\
1 & \\
Myelofibrosis type, $n$ & 6 \\
Primary MF & 3 \\
Post-ET & 1 \\
Post-PV & \\
DIPSS risk status, $n$ & 1 \\
High & 6 \\
Intermediate-2 & \\
Intermediate-1 & 3 \\
Transfusion-dependent at study entry & \\
Yes & 3 \\
No & 7
\end{tabular}

DIPSS International Working Group-Myeloproliferative Neoplasms Research and Treatment Dynamic International Prognostic Scoring System, ECOG Eastern Cooperative Oncology Group performance status, PV polycythemia vera

The JAK inhibitor (JAKi) ruxolitinib is standard treatment for intermediate- or high-risk myelofibrosis (MF), but fewer than $50 \%$ of patients achieve spleen response $(\geq 35 \%$ reduction in spleen volume) or significant improvement in symptom burden $[1,2]$.

The Hedgehog signaling pathway is involved in primitive and definitive bone marrow hematopoiesis and maintenance of hematopoietic precursors [3]. Pre-clinical and clinical data suggest that addition of a Hedgehog pathway inhibitor (HPI) to ruxolitinib may improve response $[4,6]$. The HPI vismodegib is approved for the treatment of advanced basal cell carcinoma [5].

We present findings from MYLIE, an open-label, multicenter, phase Ib study (ClinicalTrials.gov, NCT02593760) of vismodegib plus ruxolitinib in patients with intermediate- or high-risk MF.

Eligible patients were adults with pathologically confirmed primary MF, post-polycythemia vera MF, or post-essential thrombocythemia MF who were considered intermediate-1, intermediate-2, or high risk, with a peripheral blood blast count $<10 \%$ and palpable splenomegaly $>5 \mathrm{~cm}$ below the left costal margin, and who had no prior treatment with a JAKi or an HPI.

Patients received vismodegib (150 mg/day orally) and ruxolitinib (starting dose 15 or $20 \mathrm{mg}$ orally twice daily, depending on baseline platelet count) for up to 48 weeks, or until disease progression, unacceptable toxicity, or consent withdrawal.

Efficacy end points were assessed at 24 and 48 weeks after the first dose of study medication and included spleen response rate $(\geq 35 \%$ reduction in spleen volume), disease response rate (complete remission [CR] and partial remission [PR]), clinical improvement (anemia, spleen, or symptom response without disease progression or increase in severity of anemia, thrombocytopenia, or neutropenia), anemia response rate, and improvement in bone marrow fibrosis of $\geq 1$ grade (Additional file 1). Pharmacokinetics of total and unbound vismodegib were characterized using pre-dose samples obtained at weeks 6 , $12,24,36$, and 48 and were compared with data from patients with advanced basal cell carcinoma [7-9].

Ten patients were enrolled at four sites in the USA (2), Canada (1), and Italy (1) (Table 1). Patients received vismodegib plus ruxolitinib for a median of 330.0 days. Eight patients completed 48 weeks of treatment; one patient discontinued owing to lack of efficacy at 35 weeks and one because of a vismodegib-related adverse event (AE; dysgeusia) at 23 weeks.

At week 24, spleen response was observed in one and three patients by investigator and central review, respectively (Fig. 1a). At week 48, of eight patients, two and four patients had spleen response by investigator and central review, respectively.

Of seven evaluable patients, five had symptom response at week 24 (Fig. 1b). At week 48, symptom response was achieved in two patients with no previous symptom response, three patients maintained symptom response from week 24 , and two were not evaluable. No patients experienced anemia response. Of nine patients evaluable for disease response at week 24, one experienced PR, one experienced clinical improvement, and seven had stable disease. Of eight patients on study at week 48 , one maintained clinical improvement, six had stable disease, and the patient with PR had relapsed.

From baseline, no patients experienced a $\geq 1$-grade improvement in fibrosis at week 24 per central review (Additional file 1: Table S1). Of five patients with bone marrow biopsy specimens at week 48, a 1-grade improvement in fibrosis was observed in one and two patients by central review and local pathology review, respectively.

All ten patients experienced at least one $\mathrm{AE}$ (Additional file 1: Table S2): five patients (50\%) experienced grade $\geq 3 \mathrm{AEs}$, and three patients (30\%) experienced a total of six serious AEs (grade 4 anemia, grade 3 pneumonia, grade 4 sepsis, grade 3 vomiting, grade 3 lung infiltration, grade 3 infectious 


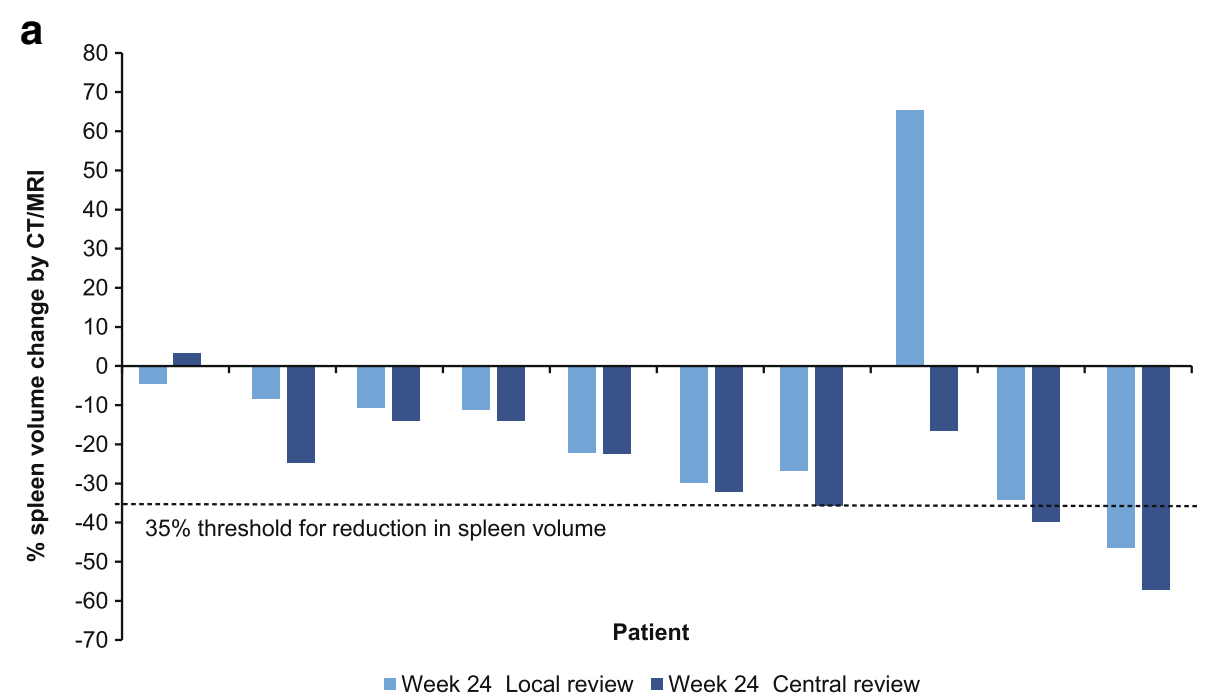

b

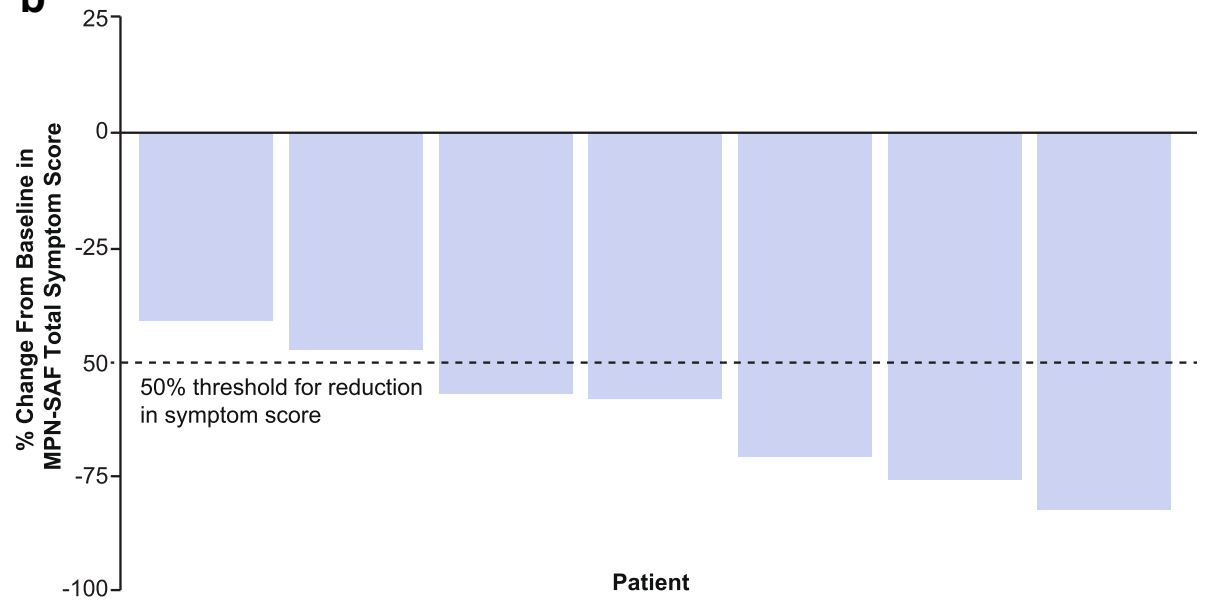

Fig. 1 Spleen volume change from baseline per central and investigator review (a) and symptom response change (b) at week 24, by patient. Threshold for clinical efficacy at 35\% reduction in spleen volume and 50\% reduction in the MPN-SAF TSS is indicated by the dotted line. Spleen volume was assessed by CT or MRI, both by a local radiologist and a central independent review committee. Symptom score data were not available for three patients, including the patient who discontinued early. CT computed tomography; MPN-SAF TSS Myeloproliferative Neoplasm Symptom Assessment Form Total Symptom Score; MRI magnetic resonance imaging

enterocolitis). No patients died during the study period. Dose interruptions or modifications are shown in Additional file 1: Table S3.

Total and unbound steady-state vismodegib plasma concentrations in patients with MF were consistent with those obtained in patients with basal cell carcinoma (Additional file 1: Table S4) [7, 8].

Vismodegib combined with ruxolitinib did not result in greater efficacy than ruxolitinib alone [1], consistent with other trials of HPIs in MF $[6,10]$. The combination was tolerable, and no new safety signals were seen. However, because of lack of evidence of a disease-modifying effect after addition of vismodegib to ruxolitinib, further evaluation of this combination will not be pursued.

\section{Additional file}

Additional file 1: Supplementary methods. Table S1. Bone marrow fibrosis grade. Table S2. Treatment-emergent AEs of any grade that occurred in $\geq 2$ patients. Table S3. AEs leading to treatment interruption or modification. Table S4. Mean ( \pm SD) total and unbound steady-state vismodegib plasma concentration. (DOCX $24 \mathrm{~kb}$ )

\section{Abbreviations}

AE: Adverse event; CR: Complete remission; CT: Computed tomography; DIPSS: International Working Group-Myeloproliferative Neoplasms Research and Treatment Dynamic International Prognostic Scoring System; ECOG: Eastern Cooperative Oncology Group performance status; HPI: Hedgehog pathway inhibitor; JAK: Janus kinase; JAKi: JAK inhibitor; MF: Myelofibrosis; MPN-SAF: Myeloproliferative Neoplasm Symptom Assessment Form; MRI: Magnetic resonance imaging; PK: Pharmacokinetics; PR: Partial remission; PV: Polycythemia vera; SAE: Serious adverse event; TSS: Total symptom score 


\section{Acknowledgements}

Third-party medical writing support was provided by Lucy Smithers, PhD (ApotheCom, London, UK) and was funded by F. Hoffmann-La Roche Ltd. The authors thank the participating investigators and patients.

\section{Funding}

This study was funded by F. Hoffmann-La Roche Ltd. The trial was designed by the sponsor (F. Hoffmann-La Roche Ltd). Data were collected by the site investigators and were retained and analyzed by the sponsor ( $F$. HoffmannLa Roche Ltd). All authors had full access to the data. FP was supported by grants of the Fondazione Regionale Ricerca Biomedica, Milan, Italy [FRRB project no. 2015-0042: genomic profiling of rare hematologic malignancies, development of personalized medicine strategies, and their implementation into the Rete Ematologica Lombarda (REL) clinical network].

\section{Availability of data and materials}

The datasets used and/or analyzed during the current study are available from the corresponding author on reasonable request.

\section{Authors' contributions}

SC, GB, WD, JC, SK, SV, GH, CH, ND, and FP interpreted the study data and contributed to writing the manuscript. MT, ND, and VM performed the data analyses. All authors read and approved the final manuscript.

\section{Ethics approval and consent to participate}

This study was conducted in full conformance with the ICH E6 Guideline for Good Clinical Practice and the principles of the Declaration of Helsinki. It was approved by the institutional review boards or ethics committees of the study sites.

\section{Consent for publication}

Not applicable.

\section{Competing interests}

GH, CH, MT, and ND are employees of F. Hoffman-La Roche Ltd., and ND holds stock in F. Hoffman-La Roche Ltd. VM is an employee of RocheGenentech, Ltd. SK reports receiving honoraria for advisory board participation, travel expenses, and research funding by Novartis, in addition to the funding of this study by F. Hoffmann-LaRoche Ltd. JC, SC, GB, WD, SV, and FP declare that they have no competing interests other than the funding of this study by F. Hoffmann-LaRoche Ltd.

\section{Publisher's Note}

Springer Nature remains neutral with regard to jurisdictional claims in published maps and institutional affiliations.

\section{Author details}

'Queen Elizabeth II Health Sciences Centre, 1278 Tower Road, Room 420, Halifax, Nova Scotia B3H 2V7, Canada. ${ }^{2}$ Azienda Ospedaliero-Universitaria Città della Salute e della Scienza di Torino, San Giovanni Battista, Corso Bramante 88/90, 10126, Torino, Italy. ${ }^{3}$ Sarah Cannon Research Institute, 250 25th Ave North, Suite 412, Nashville, TN 37203, USA. ${ }^{4}$ Florida Cancer Specialists, 1400 North US Highway 441, Suite 540, The Villages, FL 32159, USA. ${ }^{5}$ Department of Hematology, Oncology, Hemostaseology, and SCT, Faculty of Medicine, Rheinisch-Westfälische Technische Hochschule Aachen University, Pauwelsstrasse 30, 52074 Aachen, Germany. ${ }^{6}$ Department of Leukemia, The University of Texas MD Anderson Cancer Center, 1515 Holcomb Blvd., Unit 428, Houston, TX 77030, USA. ${ }^{7}$ Roche Products Ltd, 6 Falcon Way, Shire Park, Welwyn Garden City AL7 1TW, UK. ${ }^{8}$ Roche Clinical Science, F. Hoffmann-La Roche Ltd., Bldg. 001, Room 07.S373, CH-4070 Basel, Switzerland. ${ }^{9}$ Genentech Research and Early Development, Genentech, Inc., 1 DNA Way, South San Francisco, CA 94080, USA. ${ }^{10}$ Università degli Studi dell'Insubria, Viale Luigi Borri, 57, 21100 Varese, VA, Italy. ${ }^{11}$ Queen Elizabeth II Health Sciences Centre, Room 430, Bethune Building, VG Site, 126 South Park Street, Halifax, Nova Scotia B3H 2V9, Canada.
Received: 5 July 2018 Accepted: 4 September 2018

Published online: 24 September 2018

\section{References}

1. Verstovsek S, Mesa RA, Gotlib J, Levy RS, Gupta V, DiPersio JF, et al. A double-blind, placebo-controlled trial of ruxolitinib for myelofibrosis. N Engl J Med. 2012;366(9):799-807.

2. Harrison C, Kiladjian J-J, Al-Ali HK, Gisslinger H, Waltzman R, Stalbovskaya V, et al. JAK inhibition with ruxolitinib versus best available therapy for myelofibrosis. N Engl J Med. 2012;366(9):787-98.

3. Tibes R, Mesa RA. Targeting hedgehog signaling in myelofibrosis and other hematologic malignancies. J Hematol Oncol. 2014;7:18.

4. Bhagwat N, Keller M, Rampal R, Koppikar P, Shank K, De Stanchina E, et al. Improved efficacy of combination of JAK2 and hedgehog inhibitors in myelofibrosis [abstract]. Blood. 2013;122(21):s666.

5. AMA 10th. Erivedge (vismodegib) [package insert]. South San Francisco: Genentech USA, Inc.; 2017.

6. Gupta V, Harrison CN, Hasselbalch H, Pieri L, Koschmieder S, Cervantes F, et al. Phase $1 \mathrm{~b} / 2$ study of the efficacy and safety of sonidegib (LDE225) in combination with ruxolitinib (INC424) in patients with myelofibrosis [abstract]. Blood. 2015;126:825.

7. Sekulic A, Migden MR, Oro AE, Dirix L, Lewis KD, Hainsworth JD, et al. Efficacy and safety of vismodegib in advanced basal-cell carcinoma. N Engl J Med. 2012;366(23):2171-9.

8. Basset-Seguin N, Hauschild A, Kunstfeld R, Grob J, Dreno B, Mortier L, et al. Vismodegib in patients with advanced basal cell carcinoma: primary analysis of STEVIE, an international, open-label trial. Eur J Cancer. 2017;86:334-48.

9. Couban S, Benevolo G, Donnellan W, Cultrera J, Koschmieder S, Verstovsek $\mathrm{S}$, et al. Phase $1 \mathrm{~b}$ results of a study to assess the efficacy and safety of vismodegib in combination with ruxolitinib in patients with intermediateor high-risk myelofibrosis. Blood. 2017;130:4179.

10. Sasaki K, Gotlib JR, Mesa RA, Newberry K, Ravandi F, Cortes JE, et al. Phase II evaluation of IPI-926, an oral Hedgehog inhibitor, in patients with myelofibrosis. Leuk Lymphoma. 2015;56(7):2092-7.

\section{Ready to submit your research? Choose BMC and benefit from:}

- fast, convenient online submission

- thorough peer review by experienced researchers in your field

- rapid publication on acceptance

- support for research data, including large and complex data types

- gold Open Access which fosters wider collaboration and increased citations

- maximum visibility for your research: over $100 \mathrm{M}$ website views per year

At BMC, research is always in progress.

Learn more biomedcentral.com/submissions 